\title{
Genetic Tuned PID Controller Based Speed Control of DC Motor Drive
}

\author{
S. A. Deraz ${ }^{1,2}$ \\ ${ }^{1}$ Electrical Engineering Department, Faculty of Engineering, King Abdulaziz University, Rabigh, Saudi Arabia \\ ${ }^{2}$ Electrical Engineering Department, Faculty of Engineering, Menoufiya University, Shebin El-kom, Egypt
}

\begin{abstract}
Due to its extensive use for motion control systems in industry, tuning of the proportional-integral-derivative (PID) controller parameters has been the focus of intensive research. In this paper, a novel tuning method for the parameters of PID controller based speed control of DC motor using genetic algorithm (GA) is proposed. The main advantage of the proposed method is that the mathematical model of the system under control is not required, so it is useful in many industrial processes that have no obvious or complicated model. In addition, this method allows determining the best values of PID parameters for a specified overshoot, rise time, settling time, and steady-state error. The DC motor with the designed PID controller is modelled and the simulation results are obtained. The obtained results are compared with those of conventional Ziegler Nichols (ZN), GA based integral absolute of the error (IAE) index, and GA based mean of the squared error (MSE) index methods. The comparison indicates effectiveness of the proposed tuning method as it gives a better performance and satisfies the specified control characteristics.
\end{abstract}

Keywords- Genetic Algorithm (GA), PID Controller Tuning, Speed Control of DC Motor, Ziegler Nichols (ZN), Integral Absolute of the Error (IAE), Mean of the Squared Error (MSE).

\section{INTRODUCTION}

High performance electrical motor drives are very important in industrial as well as other purpose applications. In general, a better performance of an electrical motor drive system has a better dynamic response. Among all motors, DC motors have been widely used in many adjustable speed drive applications that need high control requirements such as electric vehicles, steel rolling mills, electric cranes, high precision digital tools, and robotics. This is due to their simple, precise, wide range control characteristics. Speed of the DC motors is directly proportional to the armature voltage and inversely to the magnetic field flux. Controlling the armature voltage and/or the field current will adjust the DC motor speed

One of the most popular controllers has been used for speed control of the DC motors is the PID controller due to its simple structure, and good performance. In addition, with technology advancements, PID controller parameters can be easily changed without changing any hardware. However, the performance of the PID controller depends on the accuracy of the system model and parameters. In practice, the controlled systems are usually nonlinear and hence their accurate mathematical models are not available. In addition, the system parameters can vary with the time and the operating conditions. Therefore, the tuning methods of the controller parameters are of great importance. Tuning of the PID controller parameters is to determine the parameters that satisfy the required characteristics of the controlled system. Among the conventional tuning methods, the Ziegler-Nichols (ZN) technique is the most well-known method [1-3]. It is robust against the system model uncertainty and good for many industrial applications. However, it does not provide an optimal tuning since it produces a high overshoot in the system response. To improve the performance of the conventional tuning methods, various intelligent methods have been presented [4-14]. These methods are based on Genetic Algorithm (GA), Iterative Feedback Tuning (IFT), Particle Swarm Optimization (PSO), and Fruit Fly Optimization Algorithm (FOA) techniques. These techniques are search optimization methods in which the objective functions that measure the effectiveness of the tuning methods are different. As the objective function is different, the best value of the PID controller parameters that obtained in each technique are different and hence the response of the controlled system is different. Therefore, although these techniques are quite good, the optimal response of the controlled system cannot be achieved.

In this paper, a novel tuning method for PID controller parameters based speed control of DC motor using Genetic Algorithm (GA) technique is proposed. The objective function of the proposed GA is designed based on the required control characteristics of the system under study. The system is modelled using MATLAB/SIMULINK and the simulation results are obtained and compared with those of conventional Ziegler Nichols (ZN), GA based integral absolute of the error (IAE) index, and GA based mean of the squared error (MSE) index methods. The comparison indicates the effectiveness of the proposed tuning method as it gives a better performance and satisfies the specified control characteristics.

\section{DC MOTOR MODEL}

Although their maintenance costs are higher than other motors, DC motors are most suitable motors for adjustable speed control applications that need high control requirements. Fig. 1 shows the equivalent circuit of a separately excited DC motor. The characteristics equations of the DC motor in Laplace form can be given as:

$$
\begin{gathered}
V_{a}(s)=\left[L_{a} s+R_{a}\right] I_{a}(s)+E_{b}(s) \\
E_{b}(s)=K_{e} \omega(s) \\
T_{d}(s)=K_{t} I_{a}(s)=T_{L}(s)+[j s+B] \omega(s)
\end{gathered}
$$

Where $V_{a}, I_{a}, R_{a}$, and $L_{a}$ are the armature voltage $(V)$, 
current $(\mathrm{A})$, resistance $(\Omega)$, and inductance $(\mathrm{H})$ respectively. $\mathrm{E}_{\mathrm{b}}$ is the back EMF $(\mathrm{V})$ and $\mathrm{K}_{\mathrm{e}}$ is the back EMF constant (V.sec/rad). $T_{d}$ is the developed torque (N.m), $K_{t}$ is the torque constant (N.m/A), $\omega$ is the rotational speed of the motor $(\mathrm{rad} / \mathrm{sec}), \mathrm{T}_{\mathrm{L}}$ is the load torque $(\mathrm{N} . \mathrm{m}), \mathrm{j}$ is the inertia moment of the motor $\left(\mathrm{Kg} \cdot \mathrm{m}^{2}\right)$ and $\mathrm{B}$ is the viscous friction constant (N.m.sec/rad).

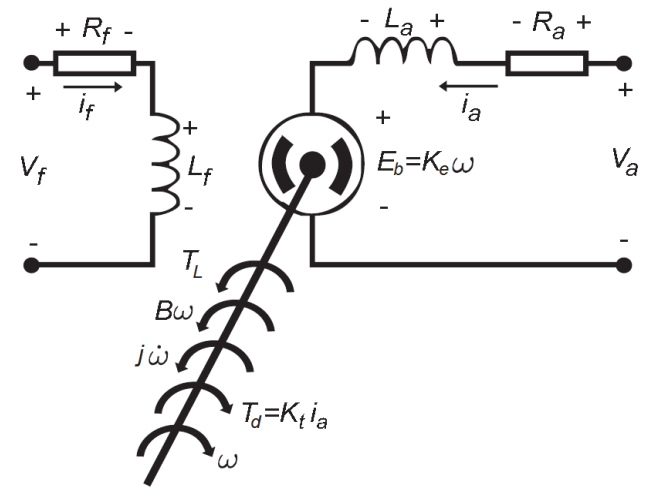

Fig. 1 Equivalent circuit of a separately excited DC motor

Fig. 2 shows the block diagram of a separately excited DC motor drive using armature voltage control. The transfer function of the motor speed with respect to the armature voltage can be given as:

$$
\frac{\omega(s)}{V_{a}(s)}=\frac{K_{t}}{\left[L_{a} j\right] s^{2}+\left[R_{a} j+L_{a} B\right] s+\left[R_{a} B+K_{e} K_{t}\right]}
$$

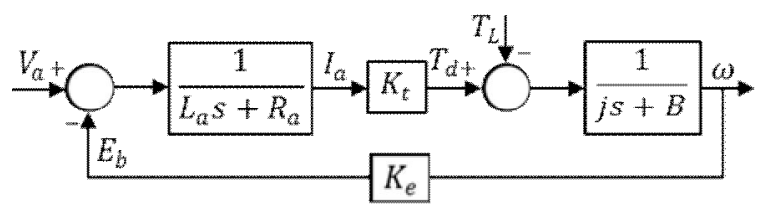

Fig. 2 Block diagram of a separately excited DC motor drive using armature voltage control

\section{PID CONTROLLER DESIGN}

The PID controller involves three parameters: the proportional gain $\left(\mathrm{K}_{\mathrm{p}}\right)$, the integral gain $\left(\mathrm{K}_{\mathrm{i}}\right)$ and the derivative gain $\left(\mathrm{K}_{\mathrm{d}}\right)$. The proportional gain provides a control action proportional to the error. The integral action reduces the steady state error. While, the derivative action improves the transient response. The sum of these three actions makes the PID controller as shown in Fig. 3. The transfer function of the PID controller can be given as:

$$
\frac{V_{a}(s)}{E(s)}=K_{p}+\frac{K_{i}}{s}+K_{d} s=K_{p}\left[1+\frac{1}{T_{i} s}+T_{d} s\right]
$$

Where $\mathrm{V}_{\mathrm{a}}$ is the armature voltage, $\mathrm{E}$ is the error between the desired speed $\left(\omega^{*}\right)$ and actual motor speed $(\omega), \mathrm{T}_{\mathrm{i}}=\mathrm{K}_{\mathrm{p}} / \mathrm{K}_{\mathrm{i}}$ is the integral time, and $\mathrm{T}_{\mathrm{d}}=\mathrm{K}_{\mathrm{d}} / \mathrm{K}_{\mathrm{p}}$ is the derivative time.

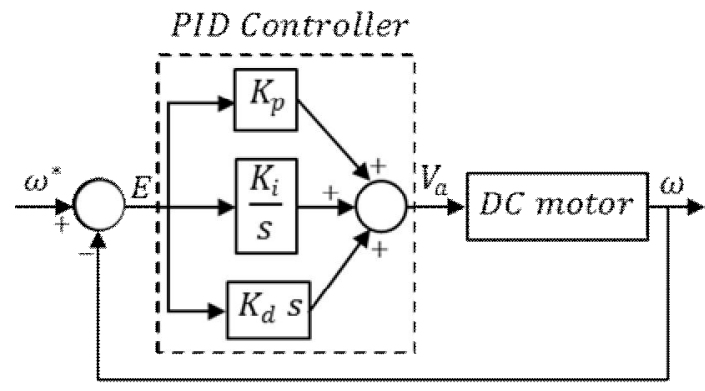

Fig. 3 Block diagram of the DC motor drive system

\section{TUNING OF PID CONTROLLER}

PID controllers have been widely used for control systems. The most critical step for applying the PID controller is the tuning of its parameters. The tuning process needs a lot of time and effort. In the worst case, the bad tuning leads to a poor performance of the controlled system. The goal of the tuning process is to determine the PID controller parameters that satisfy the performance specifications of the controlled system, such as the rising time, the maximum overshot, the settling time and the steady state error. However, it is difficult to obtain the desirable values of these requirements simultaneously. As shown in Table I, for example, larger values of proportional gain results in faster response while overshoot is increased. Therefore, an optimum tuning technique is of great importance.

TABLE I

EFFECTS OF INCREASING THE PID CONTROLLER PARAMETERS

\begin{tabular}{|l|l|l|l|l|}
\hline $\begin{array}{l}\text { Para- } \\
\text { meter }\end{array}$ & Rise time & Overshoot & $\begin{array}{l}\text { Settling } \\
\text { time }\end{array}$ & $\begin{array}{l}\text { Steady } \\
\text { state error }\end{array}$ \\
\hline $\mathrm{K}_{\mathrm{p}}$ & Decrease & Increase & $\begin{array}{l}\text { Small } \\
\text { change }\end{array}$ & Decrease \\
\hline $\mathrm{K}_{\mathrm{i}}$ & Decrease & Increase & Increase & Eliminate \\
\hline $\mathrm{K}_{\mathrm{d}}$ & $\begin{array}{l}\text { Small } \\
\text { change }\end{array}$ & Decrease & Decrease & $\begin{array}{l}\text { Small } \\
\text { change }\end{array}$ \\
\hline
\end{tabular}

\section{A. ZN Tuning Method}

Ziegler and Nichols presented simple mathematical procedures to tune the parameters of the PID controller. These procedures have been accepted as a standard tuning method in the control systems. $\mathrm{ZN}$ method is applied on the plants whose step response of the form shown in Fig. 4. By drawing a tangent line at the inflection point of the step response of the plant, parameters $\mathrm{K}, \mathrm{L}$, and $\mathrm{T}$ (or $\mathrm{a}=\mathrm{KL} / \mathrm{T}$ ) can be obtained. Hence, the parameters of the PID controller can be calculated using Table II. 


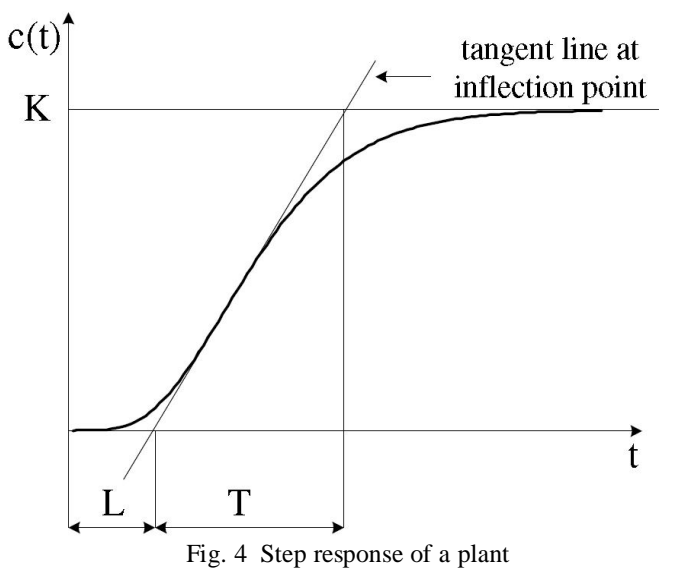

TABLE II

ZIEGLER NICHOLS TUNING RULES

\begin{tabular}{|l|c|c|c|}
\hline \multirow{2}{*}{$\begin{array}{l}\text { Controller } \\
\text { type }\end{array}$} & \multicolumn{3}{|c|}{ Controller parameters } \\
\cline { 2 - 4 } & $\boldsymbol{K}_{\boldsymbol{p}}$ & $\boldsymbol{T}_{\boldsymbol{i}}$ & $\boldsymbol{T}_{\boldsymbol{d}}$ \\
\hline $\mathrm{P}$ & $1 / \mathrm{a}$ & & \\
\hline $\mathrm{PI}$ & $0.9 / \mathrm{a}$ & $\mathrm{L} / 0.3$ & \\
\hline $\mathrm{PID}$ & $1.2 / \mathrm{a}$ & $\mathrm{L} / 0.5$ & $0.5 \mathrm{~L}$ \\
\hline
\end{tabular}

\section{B. GA Tuning Method}

GA is an optimization search method that mimics the mechanism of natural evolution. It has been successively used to optimize many different complex problems. In this paper, GA is used to determine the optimum values of the PID controller parameters that satisfy the required dynamic performance characteristics of the DC motor drive system. Fig. 5 shows the flowchart of GA based tuning of PID controller parameters. In the first, GA is initialized. Then, it creates an initial population of PID controller parameters. The population is generated randomly, covering the entire range of possible solutions. The population is composed of chromosomes. Each chromosome is a candidate solution to the problem. Fig. 6 shows the chromosome structure, in which the three parameters $\left(\mathrm{K}_{\mathrm{p}}, \mathrm{K}_{\mathrm{i}}\right.$ and $\left.\mathrm{K}_{\mathrm{d}}\right)$ are included. The chromosomes are applied in the DC drive plant and the dynamic performance characteristics of the plant are determined for each chromosome. Then, the fitness value for each chromosome is evaluated using the objective function. Based on the fitness values of the first generation, a group of best chromosomes is selected to create the next population. After selection, crossover and mutation are applied to this surviving population in order to improve the next generation. The process continues until the termination criterion is achieved or the number of generations is reached to its maximum value.

\section{SiMULATION RESULTS AND DISCUSSION}

The open loop and closed loop models of the DC motor under study are developed using MATLAB/SIMULINK software package. In the closed loop controlled DC motor, the pure derivative action in the PID controller is not usually used directly due to the undesirable noise amplification. Therefore, the derivative action of the PID controller is replaced by a first-order model with a lag. The transfer function of the approximated PID controller that shown in Fig. 7 can be written as:

$$
P I D_{T F}=K_{p}+\frac{K_{i}}{s}+\frac{K_{d} s}{\frac{K_{d} s}{N}+1}
$$

Where $\mathrm{N}$ is a positive large number. The value of $\mathrm{N}$ is taken equals 100 in order to obtain a good PID approximation. In this study, the required control characteristics of the DC motor can be summarized in Table III.

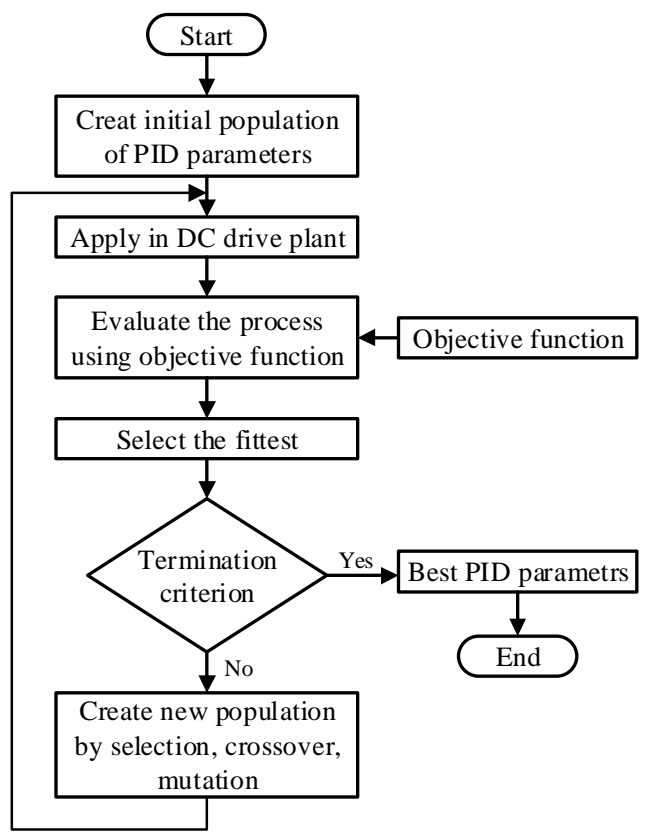

Fig. 5 Flow chart of GA based tuning of PID controller parameters

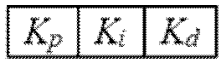

Fig. 6 Chromosome structure

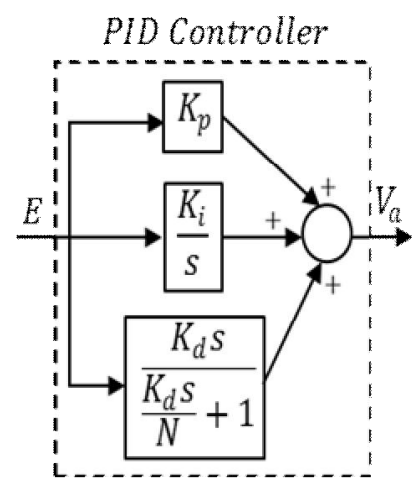

Fig. 7 Approximated PID controller 
TABLE III

REQUIRED CONTROL CHARACTERISTICS

\begin{tabular}{|l|l|}
\hline Parameter & Value \\
\hline Rise time (sec.) & $<0.01$ \\
\hline Settling time (sec.) & $<0.05$ \\
\hline Maximum overshoot (\%) & $<5$ \\
\hline Steady state error (\%) & $< \pm 0.1$ \\
\hline
\end{tabular}

\section{A. Application of ZN Tuning Method}

In order to determine the parameters of the PID controller using the $\mathrm{ZN}$ tuning method, a MATLAB $\mathrm{m}$-file is developed. The flowchart of the developed program is shown in Fig. 8. The step response of the uncontrolled DC motor is shown in Fig. 9. It is clear that the uncontrolled DC motor has a slow step response since the rise time equals 0.098 second and a steady state error equals $1.85 \%$ of the reference speed. The inflection point is determined, the tangent line is drawn, and the PID controller parameters is determined using $\mathrm{ZN}$ rules.

\section{B. Application of GA Tuning Method}

The most important step in applying GA tuning method is to choose the objective function that is used to evaluate the fitness value of each chromosome. In this paper, three objective functions are used and their performance are compared. The first is based on integral of the absolute error (IAE) index, the second is based on mean of the squared error (MSE) index, and the third is the proposed objective function (Fobj) which is designed according to the required control characteristics. The three objective functions can be given as:

$$
\begin{gathered}
I A E=\int_{0}^{T}|e(t)| d t \\
M S E=\frac{1}{t} \int_{0}^{T}(e(t))^{2} d t \\
F_{o b j}=|O S \%-5|+m\left(\left|t_{s}-0.05\right|+\left|t_{r}-0.01\right|\right)+n|| E_{s s}|-0.001|(9)
\end{gathered}
$$

Where OS is the maximum overshoot of the controlled system response, $t_{\mathrm{s}}$ is the settling time, $t_{\mathrm{r}}$ is the rise time, and $\mathrm{E}_{\mathrm{ss}}$ is the steady state error. The constants $\mathrm{m}$ and $\mathrm{n}$ are weights and are taken as $(m=100, n=150)$. The parameters of GAs in this study are set as in Table IV. The GA optimization process based IAE index, MSE index, and proposed index are shown in Fig. 10, Fig. 11, and Fig. 12 respectively. For each case, the PID controller parameters is determined.

TABLE IV

SETTINGS OF GA PARAMETERS VALUES

\begin{tabular}{|l|l|}
\hline Parameter & Value \\
\hline Populations & 20 \\
\hline Generations & 50 \\
\hline Ranges of PID parameters & $0 \sim 1000$ \\
\hline Crossover fraction & 0.8 \\
\hline Mutation rate & 0.01 \\
\hline Elite count & 5 \\
\hline
\end{tabular}

\section{Start}

1

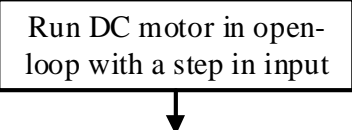

Determine the step response of the speed

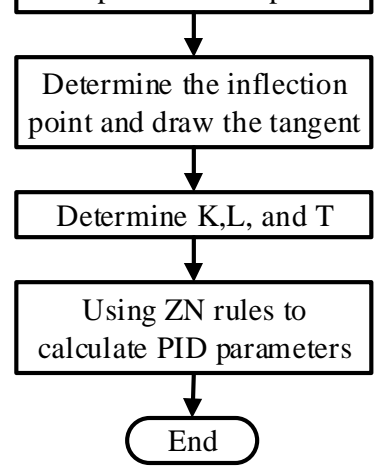

Fig. 8 Flow chart of MATLAB program for ZN tuning method

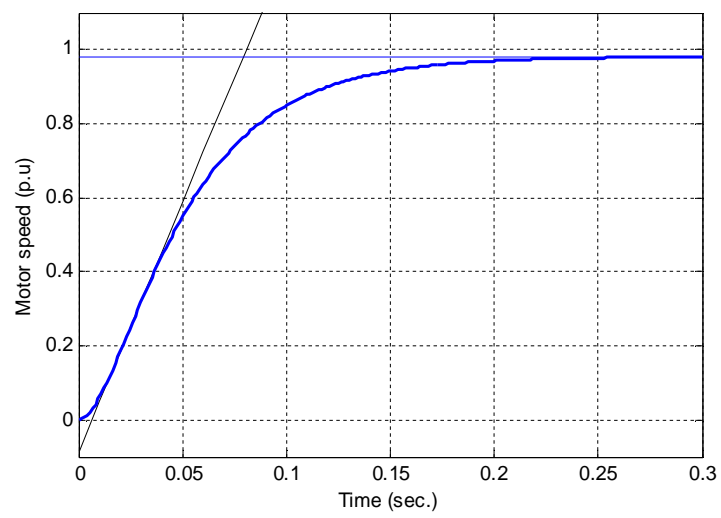

Fig. 9 Step response of the uncontrolled DC motor
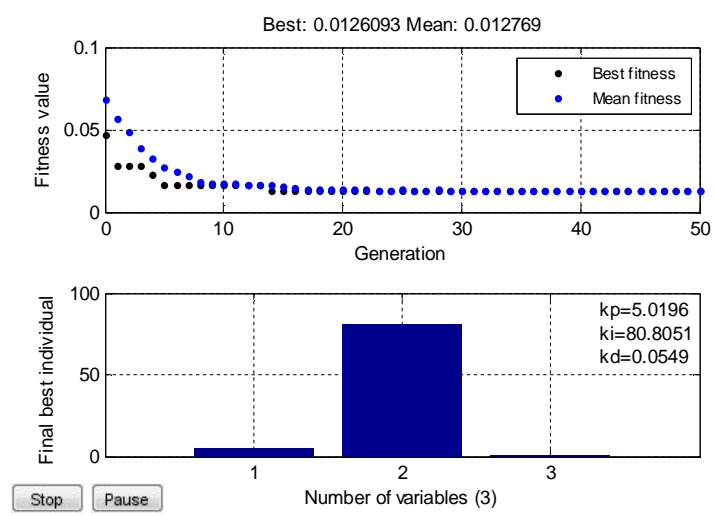

Fig. 10 GA optimization process based IAE index 

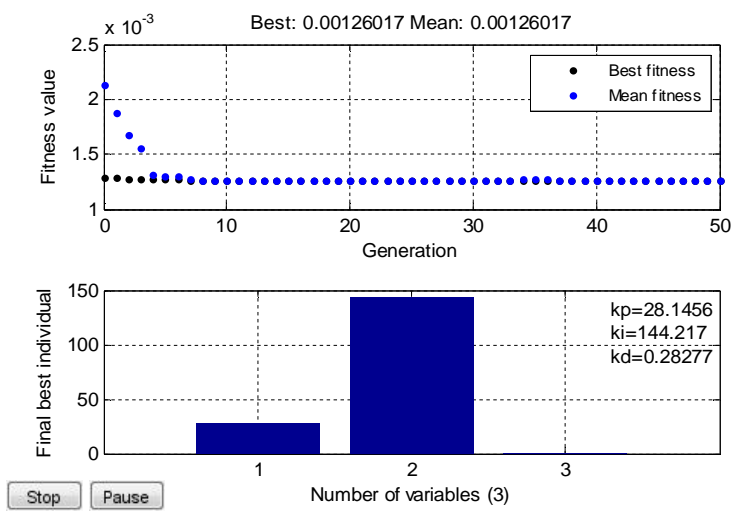

Fig. 11 GA optimization process based MSE index
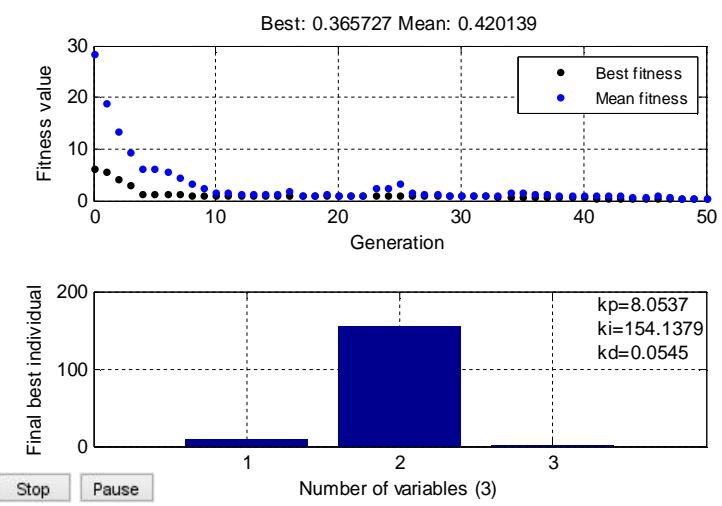

Fig. 12 GA optimization process based the proposed index

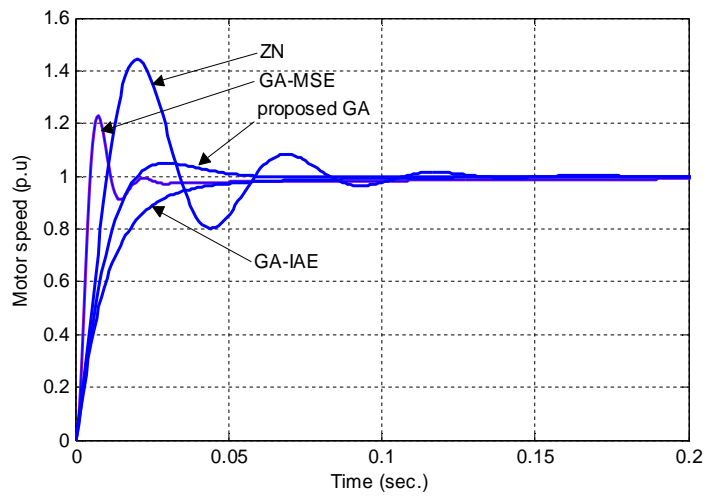

Fig. 13 Step response of controlled DC motor drive

\section{CONCLUSIONS}

This paper presents a novel tuning method for the PID controller parameters using genetic algorithm (GA) based speed control of DC motor. The objective function of the proposed genetic algorithm is designed according to the required control characteristics of the drive system. The controlled DC motor is modelled and its response with the proposed GA tuning technique are obtained. The proposed GA tuning method has a better performance compared with the conventional $\mathrm{ZN}$ tuning method, and the traditional GAs based IAE and MSE indexes. The proposed method gives a better response and satisfies the specified control characteristics of the controlled DC motor drive system. Further, it is very useful for non-linear, complex, and unrealizable parameters systems.

TABLE V

PERFORMANCE COMPARISON

\begin{tabular}{|c|c|c|c|c|}
\hline \multirow[t]{3}{*}{ Parameter } & \multicolumn{4}{|c|}{ Tuning method } \\
\hline & \multirow[t]{2}{*}{$Z N$} & \multicolumn{3}{|c|}{$G A$} \\
\hline & & $I A E$ & $M S E$ & Proposed \\
\hline $\mathrm{K}_{\mathrm{p}}$ & 13.7312 & 5.0196 & 28.1456 & 8.0537 \\
\hline $\mathrm{K}_{\mathrm{i}}$ & 1061.89 & 80.8051 & 144.217 & 154.1379 \\
\hline $\mathrm{K}_{\mathrm{d}}$ & 0.04439 & 0.0549 & 0.28277 & 0.0545 \\
\hline OS (\%) & 44.3262 & 0 & 22.7010 & 4.995 \\
\hline $\mathrm{t}_{\mathrm{r}}(\mathrm{sec})$. & 0.00775 & 0.0249 & 0.0032 & 0.0136 \\
\hline $\mathrm{t}_{\mathrm{s}}(\mathrm{sec})$. & 0.1243 & 0.0892 & 0.2011 & 0.0499 \\
\hline $\mathrm{E}_{\mathrm{ss}}(\%)$ & $6.8 \mathrm{e}-04$ & 0.1442 & 0.5937 & $1.39 \mathrm{e}-03$ \\
\hline
\end{tabular}

\section{APPENDIX}

DC motor, separately-excited, 5Hp, 240V, $1750 \mathrm{rpm}$, $\mathrm{R}_{\mathrm{a}}=2.581 \Omega, \quad \mathrm{L}_{\mathrm{a}}=0.028 \quad \mathrm{H}, \quad \mathrm{K}_{\mathrm{t}}=\mathrm{K}_{\mathrm{e}}=1.01134 \quad \mathrm{~V} /(\mathrm{rad} / \mathrm{sec})$, $\mathrm{j}=0.02215 \mathrm{Kg} \cdot \mathrm{m}^{2}, \mathrm{~B}=0.002953 \mathrm{~N} /(\mathrm{rad} / \mathrm{sec})$.

\section{REFERENCES}

[1] J.G. Ziegler, N. B. Nichols, Optimum Settings for Automatic Controllers, Trans. ASME, Vol. 64, No. 8, pp. 759-768, 1942.

[2] P. M. Meshram, R. G. Kanojiya, Tuning of PID Controller Using Ziegler-Nichols Method for Speed Control of DC motor, in Proceedings book IEEE International Conference On Advances In Engineering, Science And Management (ICAESM), pp. 117-122, Mar. 2012

[3] S. Das, A. Chakraborty, J. K. Ray, S. Bhattacharjee, B. Neogi, Study on Different Tuning Approach with Incorporation of Simulation Aspect for $Z-N$ (Ziegler-Nichols) Rules, International Journal of Scientific and Research Publications, vol. 2, Issue 8, Aug. 2012.

[4] Jin-Sung Kim, Jin-Hwan Kim, Ji-Mo Park, Sung-Man Park, WonYong Choe, Hoon Heo, Auto Tuning PID Controller based on Improved Genetic Algorithm for Reverse Osmosis Plant, World Academy of Science, Engineering and Technology, No. 23, 2008.

[5] H. Zhang, Y. Cai, Y. Chen, Parameter Optimization of PID Controllers Based on Genetic Algorithm, in Proceedings book International Conference on E-Health Networking, Digital Ecosystems and Technologies, pp. 47-49, 2010.

[6] N. P. Adhikari, M. Choubey, R. Singh, Dc Motor Control Using Ziegler Nichols and Genetic Algorithm Technique, International Journal of Electrical, Electronics and Computer Engineering, Vol. 1, pp. 33-36, 2012

[7] B. Allaoua, A. Laoufi, B. Gasbaoui, A. Nasri, A. Abderrahmani, Intelligent Controller Design for DC Motor Speed Control based on Fuzzy Logic-Genetic Algorithms Optimization, Leonardo Journal of Sciences, Issue 13, p. 90-102, July-Dec. 2008.

[8] A. R. Singh, V. K. Giri, Design and Analysis of DC Motor Speed Control by GA Based Tuning of Fuzzy Logic Controller, International Journal of Engineering Research \& Technology (IJERT), Vol. 1, Issue 5, July 2012.

[9] E.Gowthaman, C. D. Balaji, Self Tuned PID Based Speed Control of $P M D C$ Drive, in Proceedings book International Multi-Conference on Automation, Computing, Communication, Control and Compressed Sensing (iMac4s), pp. 686-692, Mar. 2013. 
International Journal of Engineering Trends and Technology (IJETT) - Volume 17 Number 2 - Nov 2014

[10] You-Bo Wang, Xin Peng, Ben-Zheng Wei, A New Particle Swarm Optimization Base Auto-Tuning of PID Controller, in Proceedings book of the Seventh International Conference on Machine Learning and Cybernetics, Kunming, pp. 1818-1823, July 2008.

[11] S. J. Bassi, M. K. Mishra, E. E. Omizegba, Automatic Tuning of Proportional-Integral-Derivative (PID) Controller Using Particle Swarm Optimization (PSO) Algorithm, International Journal of Artificial Intelligence \& Applications (IJAIA), Vol.2, No.4, pp. 24-34, Oct. 2011.

[12] J. Han, P. Wang, X. Yang, Tuning of PID Controller Based on Fruit Fly Optimization Algorithm, in Proceedings book of 2012 IEEE International Conference of Mechatronics and Automation (ICMA), Changdu, China, pp. 409-413, Aug. 2012.

[13] S. Abedini, H. Zarabadipour, Tuning of an optimal PID controller with iterative feedback tuning method for DC motor, in proceedings book of $2^{\text {nd }}$ International Conference on Control and Automation (ICCIA), pp. 611-615, Dec. 2011.

[14] Y. K. Soni, R. Bhatt, BF-PSO optimized PID Controller design using $I S E$, IAE, IATE and MSE error criteria, International Journal of Advanced Research in Computer Engineering \& Technology (IJARCET), Vol. 2, Issue 7, July 2013. 